attention to the problem of developing a service that is both effective and one that patients choose to attend. They highlight that a significant proportion may only engage in a collaborative model at a primary care level. One of the first reasons for this is the terminology prevalent in this field. ${ }^{2}$ The patients find 'somatoform' and 'medically unexplained' symptoms unsatisfactory terms which have connotations that it is all in the mind'. They wonder if the low referral rate from some general practitioners (GPs) and the non-attendance by nearly a quarter of patients referred is related to this. When developing pilot services for MUS, we chose to call our service the 'symptom management clinic' and locate it within GP surgeries, to avoid prejudicing its acceptability by alignment with mental health hospitals or psychological terminology. On auditing our attendees, many said they 'would not have attended a clinic located with a mental health provider' and we achieved high user satisfaction ratings for the ease of accessibility and format of the clinic

We also incorporated the proactive identification that Röhricht \& Elanjithara call for. We decided to 'case find' and asked GPs in four separate surgeries to identify any patients that had been seen at the surgery more than 10 times in 2 years; had at least two negative diagnostic tests; and were not currently involved with specialist mental health services. We then examined case notes and excluded patients with current diagnostic codes on the GP database. This process was time consuming, although it has future potential to be automated, but it did have the benefit of finding patients who had not been thought by the GP as having MUS but were actually presenting and being referred for repeated investigations without a diagnosis. Similarly, Burton et $a l^{3}$ used repeated referrals to secondary care as a guide and found that 'at least three times in 5 years' identified MUS patients with high levels of secondary care usage.

In one surgery alone, we identified 17 patients who had 286 out-patient and hospital attendances between them over 2 years with an average cost of $E 2396 /$ year (range $E 374-$ 7403). Of these referrals, 13 patients attended a symptom management clinic appointment with a consultant in liaison psychiatry or a consultant clinical neuropsychologist. Involvement of the GP was considered crucial, with a short feedback session with both GP and patient following the clinic to develop a collaborative approach to ongoing management. This also provided a concurrent training benefit for GPs which they valued.

A cost analysis of the patient's healthcare usage before the symptom management clinic and for 2 years following assessment used standard hospital tariff costs and showed a reduction of $48 \%$ in secondary care usage alone. We also showed an increase in functioning, as measured by the EuroQol-5D (EQ-5D), and some evidence of a reduction in Hospital Anxiety and Depression Scale (HADS). Around half of the patients went on to access psychotherapy via the improving access to psychological therapies (IAPT) pathway and other established programmes such as pain management, but many remained managed in primary care alone (details available from the author on request).

We look forward to commissioners placing some confidence and resources in these preliminary MUS services to encourage learning and development of methods for improved identification and adequate treatment of this large, neglected and often costly patient group. ${ }^{4}$
1 Röhricht F, Elanjithara T. Management of medically unexplained symptoms: outcomes of a specialist liaison clinic. Psychiatr Bull 2014; 38: 102-7.

2 Creed F, Kronke K, Hennningsen P, Gudi A, White P. Evidence-based treatment. In Medically Unexplained Symptoms, Somatisation and Bodily Distress. Developing Better Clinical Services (eds F Creed, P Henningsen, P Fink): p. 69-96. Cambridge University Press, 2011.

3 Burton C, McGorm K, Richardson G, Weller D, Sharpe M. Healthcare costs incurred by patients repeatedly referred to secondary medical care with medically unexplained symptoms: a cost of illness study. J Psychosom Res 2012; 72: 242-7.

4 Andersen NL, Eplov LF, Andersen JT, Hjorth CR, Birket-Smith M. Health care use by patients with somatoform disorders: a register-based follow-up study. Psychosom 2013; 54: 132-41.

Joanna S. Bromley, consultant liaison psychiatrist, email: jbromley@ nhs.net, and Ann Turner, clinical psychologist in neurorehabilitation, both at Devon Partnership NHS Trust, Wonford House, Exeter, UK.

doi: $10.1192 / p b .38 .6 .307 a$

\section{Insulin coma therapy: let's be factual}

There are factual errors in Dr Alan Gibson's letter in the August 2014 issue. ${ }^{1}$ By the time he worked, as he says, in the 'intellectual giant', Martin Roth's insulin unit, 1956-1959, my two papers which showed there was, over 20 years, no serious evidence for insulin coma being of any value in schizophrenia 'The insulin myth'2 and 'Insulin coma in decline' ${ }^{3}$ - had both been published and were being acted upon worldwide. However, Roth in his psychiatry textbook in 1961, a few years later, made no mention of any of this but actually still continued to advocate insulin coma therapy as if there were nowhere any doubts about it.

However, I was indebted to Martin Roth for sponsoring my resolution at the World Psychiatric Association in 1973 to expel the Soviet Association for permitting the imprisonment of political dissidents in Soviet mental hospitals.

1 Gibson A. Insulin coma therapy. Psychiatr Bull 2014; 38: 198

2 Bourne H. The insulin myth. Lancet 1953; 2: 964.

3 Bourne H. Insulin coma in decline. Am J Psychiatry 1958; 114: 1015

Harold Bourne FRCPsych, Emeritus Consultant Psychiatrist, Charing Cross Hospital, London, and Medico Chirurgo, Rome, Italy, email: drhbourne@gmail.com

doi: $10.1192 / \mathrm{pb} .38 .6 .308$

\section{Response to review of Play: Experiential Methodologies}

We are writing in response to the review by Sabina Dosani your journal had published on Play: Experimental Methodologies in Developmental and Therapeutic Settings, edited by Shubada Maitra \& Shekhar Seshadri, Orient Blackswan Private Ltd, 2012, $\$ 29.95$ (pb), 264 pp., ISBN: 9788125047599.

At least, this was the title used in the review that appeared in the Psychiatric Bulletin, April 2014, Volume 38, Issue 2.

First and most importantly, the reviewer has the title of the book wrong. The title of the book is: Play: Experiential Methodologies in Developmental and Therapeutic Settings, i.e. the word is 'experiential' not 'experimental'. This is critical as the reviewer has moved on to critiquing the book based on her

${ }^{\dagger}$ See correction, p. 312, this issue. 
erroneous understanding that it is about experimental methodologies - which it is not, as stated even in the title!

The reviewer says 'My first gripe with this book is the subtitle: "Experimental Methodologies in Developmental and Therapeutic Settings". Readers of this journal know an experiment is a study of cause and effect. It differs from non-experimental methods in that it involves the deliberate manipulation of one variable, while trying to keep all other variables constant. There are no experimental methodologies described in this book.'

Very true that no experimental methodologies are described in this book! The methodologies described are experiential methodologies - as discussed in the introduction, the book invited 'field practitioners working with children and academicians from the field of child and adolescent mental health to write and share their experiences' and that 'This volume maps the tapestry of play across settings, populations and methods'.

'My second quibble is with this book's use of the term "play". Throughout the text, play means so many disparate things, which are sometimes used as synonyms when they ought not to be. "Play" encompasses working with creative arts, using child-friendly assessment tools, exploring displacement using puppets, observing children with dolls, engaging them with games and using drama as an educational tool in a school campaign to combat sexism', says your esteemed reviewer.

Why is this a quibble? The objective of the book is to 'document work with children using various forms of play and art', and to 'bring to centre-stage the numerous field based innovations of working with children' (stated in the introduction). Further, the introduction clearly provides a definition of play: 'Broadly, the term play includes both structured and unstructured activities ranging from the use of art, puppets, dolls, games, drama and theatre, to songs and music.'

Besides, even at 'quibble' stage, the reviewer does not seem to have realised her first error about the title and subject of the book, i.e. she does not seem to have reflected on the fact that it is unlikely that a book on 'experimental methodologies' would have been talking about a range of qualitative methods!

The reviewer is certainly welcome to have 'gripes' and 'quibbles' about a book but had these been about the quality of the book, the nature of the methods and how effectively they were used, and whether the book had any learning implications for practice, her critique would have been useful. However, this necessitated correct reading of the title and an understanding of the subject of the book, as clearly elucidated in the introduction.

Considering that the reviewer misread the title of the book and completely misunderstood its subject, the rest of the review is completely invalid. The remaining part only serves to reflect her continued confusions and a lack of knowledge on the domain of creative methods and play work with children as operationally defined in this book. In the light of her gross error, the sarcastic and pompous tone she uses in the review is quite ironic!

We are also concerned that a respectable journal such as yours published a book review without checking that the title was correct (we note that the name of the first author was also misspelled).

As regular readers of your journal, and as the institutions with which we are affiliated (Tata Institute of Social Sciences and NIMHANS) regularly subscribe to your journal, we have always believed that your publications have been accurate, of high quality ensuring editorial checks and balances. However, currently, we are deeply disappointed in your publication. We trust you will take the necessary actions to re-instate our faith.

Shubhada Maitra PhD, Professor, Centre for Health and Mental Health School of Social Work, Tata Institute of Social Sciences, Mumbai, India. Shekhar Seshadri MD, DPM, Professor, Department of Child and Adolescent Psychiatry, NIMHANS, Bengaluru, India.

doi: $10.1192 / p b .38 .6 .308 a$ 